Article

\title{
Isolation and characterisation of bacteriophages with lytic activity against virulent Escherichia coli O157:H7: potential bio-control agents
}

\author{
Muyiwa Ajoke Akindolire ${ }^{1}$ and Collins Njie Ateba ${ }^{2, *}$ \\ 1 Department of Microbiology, School of Biological Sciences, Faculty of Natural and Agricultural Sciences, \\ North-West University, Private Bag X2046, Mmabatho, South Africa; bonajoke@yahoo.com \\ 2 Department of Microbiology, School of Biological Sciences, Faculty of Natural and Agricultural Sciences, \\ North-West University, Private Bag X2046, Mmabatho, South Africa; collins.ateba@nwu.ac.za \\ * Correspondence: collins.ateba@nwu.ac.za; Tel.: +27-18-389-2247 (ext. 892247)
}

\begin{abstract}
Bacteriophages can provide alternative measures for the control of E. coli O157:H7 that is currently an emerging food-borne pathogen of severe public health concern. This study was aimed at characterising E. coli O157:H7 specific phages as potential biocontrol agents for these pathogens. Fifteen phages were isolated and screened against 69 environmental E. coli O157:H7. Only 3 phages displayed broad lytic spectra against environmental shiga toxin-producing E. coli O157:H7 strains. These 3 lytic phages were designated V3, V7 and V8. Subsequent characterization indicated that they displayed very high degree of similarities despite isolation from different locations. Transmission Electron microscopy (TEM) of the phages revealed that they all had isometric heads of about $73-77 \mathrm{~nm}$ in diameter and short tails ranging from $20-25 \mathrm{~nm}$ in diameter. Phages V3, V7 and V8 were assigned to the family Podoviridae based on their morphology. Pulsed field gel electrophoresis (PFGE) genome estimation of the 3 phages demonstrated identical genome sizes of $\sim 69 \mathrm{~nm}$. The latent periods of these phages were $20 \mathrm{~min}, 15 \mathrm{~min}$, and $20 \mathrm{~min}$ for V3, V7 and V8 respectively while the burst sizes were 374,349 and $419 \mathrm{PFU} /$ infected cell respectively. While all the phages were relatively stable over a wide range of salinity, temperatures and $\mathrm{pH}$ values, their range of infectivity or lytic profile was rather narrow on environmental E. coli O157:H7 strains isolated from cattle faeces. This study showed that the Podoviridae bacteriophages are the dominant E. coli O57:H7-infecting phages harboured in cattle faeces in the North-West Province of South Africa and due to their favourable characteristics can be exploited in the formulation of phage cocktails for the bio-control of E. coli O157:H7 in meat and other meat products.
\end{abstract}

Keywords: Bacteriophages; Bio-control; E. coli O157:H7; Podoviridae; TEM, safety

\section{Introduction}

Despite the current decontamination strategies employed to inactivate bacterial pathogens especially E. coli O157:H7 in the food chain, cases of foodborne infections and even deaths associated with the consumption of food contaminated with E. coli O157:H7- occur regularly in many countries throughout the world [1-3]. Most E. coli O157:H7 infections are associated with foods of animal origin and dairy products [4], contaminated meat [5], mince beef products [4] and fresh produce [6, 7]. However, ground beef is still the most frequently implicated source of E. coli O157:H7 infections and 
has been implicated in over $75 \%$ of outbreaks recorded worldwide [4, 7]. Although the majority of outbreaks occur in developed countries, some sporadic cases of infections and outbreaks have also been reported in developing countries [1, 2, 8-14]. In contrast to developed nations, African countries are faced with the problem of poor health systems and inefficient surveillance or pathogen tracking systems exacerbating the burden of disease in these nations. In addition, the frequent occurrence of E. coli O157:H7 infections is a serious additional problem to disease-burden of these nations and thus requires effective control measures.

In order to curb public health problems associated with E. coli O157:H7 contamination in meat, a number of preservation procedures and decontamination strategies have been utilized and continue to be developed and implemented [15-18]. Presently, conventional decontamination procedures, including but not limited to heat treatments, chemical wash, and irradiation have been applied to meat carcasses to reduce bacterial contamination [16]. Although some success has been reported with the application of these methods especially when combined in a multiple hurdle approach, limitations do exist for others. For instance, the application of some physical methods such as steaming and hot water washing as bacteria control strategies has been observed not only to be costly operations but also have a negative effect on appearance and quality of meat carcasses resulting in consumer rejection [19]. In the same way, the application of some chemical compounds as a decontamination procedure is also limited by several factors such as their non-selective mode of action against a wide range of microorganism, negative effect on sensory properties of meat, the detrimental effects of chemical residues to the health of workers as well as their corrosiveness that could impact the food processing environment $[19,20]$. Moreover, the common use of chemical sanitizers has been shown to select for resistant strains rendering this procedure less effective [21].

Against this background, there is the need to develop other environmentally safe strategies that are effective at reducing or eliminating bacteria pathogens particularly Shiga-toxin producing E. coli O157:H7 strains on beef carcasses, meat and at the same time do not have a negative effects on the nutritional and sensory properties of the final raw food products as opposed to chemical and physical treatments. Recently, there has been growing interest in the use of lytic bacterial viruses also known as bacteriophages as biocontrol agents in humans, animals, plants and in food products because of their enormous antibacterial properties [22-24]. In addition to their bactericidal ability, they do not change the structure, odour and flavour of food products and are considered safe in humans since they can only target susceptible bacterial cells. Moreover, bacteriophages can self-replicate thus do not require repeated dosage and they are present almost everywhere in the environment where they can easily be isolated [22-24].

In the search for phages, it has been demonstrated that the chances of isolating them are higher where their hosts are highly prevalent, thus for phages infecting pathogens such as E. coli O157:H7 whose normal reservoir is the GIT of cattle, faeces of this ruminant represent an ideal source for isolation [25]. Numerous studies have reported the isolation of faecal-originating phages infecting $E$. coli $\mathrm{O} 157$ from countries all over the world including USA, UK, Canada, Spain [25-28]. The prevalence of phages in animals that was reported in these studies varies from one region to another with prevalence ranging from $10 \%-28 \%$ but in some cases going up as high as $49 \%$ [29, 30]. The disparity in the abundance of phages in faecal sources could be as a result of monthly variations in the population of E. coli as well as E. coli O157:H7 in both the GIT of animals and the environment [25]. Nonetheless, these studies, have demonstrated that phages are most often present in the environment 
when their bacteria hosts are also present which then stimulates the need to continuously assess their bio-control potentials against antibiotic and virulent bacteria strains like E. coli O157:H7.

Given this renewed interest on phage biocontrol of pathogens in food products, several phagebased products that have shown considerable potential have been approved for use and are already commercially available in the market in countries like North-America and Europe. LISTEX ${ }^{\text {TM P100 }}$ and Listshield ${ }^{\mathrm{TM}}$ (LMP-103 TM) which have been approved by the US Department of Agriculture (USDA) for the control of Listeria monocytogens and EcoShield ${ }^{\mathrm{TM}}$ has also been permitted for the control E. coli O157:H7. Similarly, SalmoFresh another phage-based preparation received Generally Recognised as Safe (GRSA) recognition from the FDA in 2013 for direct applications onto meat products and fresh produce. In the West, all these products have been received and applied by the food producers as natural antimicrobials employed in reducing the risk of food-borne human diseases due to the consumption of contaminated foods.

However, in Africa there is little or no information on the application of phages in the food sector due to the fact that our understanding of bacteriophages and their possible biocontrol potential is limited. In addition, the lack of reports on phage studies in most developing countries could be attributed to the ultramicroscopic nature of viruses making them difficult to handle in standard microbiology laboratories present in these countries. Therefore, phage research in Africa is relatively new and few studies have been reported in which these bio-control agents were isolated from the environment. Despite the fact that a few reports have described the isolation and characterisation of phages infecting Bacillus, Pseudomonas, Enterobacteria and S. aureus [31, 32], to the best of our knowledge there have been no studies on the isolation and characteristics of phages infecting E. coli O157:H7. Therefore, this study is the first to present a detailed report on the isolation of strictly lytic (virulent) phages with antibacterial activity against environmental virulent E. coli O157:H7 isolates from cattle in some randomly selected farms in the North-West province (South Africa). In order for these phages to be considered suitable candidates for biocontrol applications, they were further characterised based on their infectivity range, morphology, growth parameters and the stability of the phage preparations in situ under different conditions as well as assessment of their genomic analysis. The main intention is to develop bacteriophage-based treatments that would be potentially useful in the biocontrol of E. coli O157:H7.

\section{Materials and Methods}

\subsection{Bacterial Strains}

Phages were isolated from cattle faeces in farms using environmental E. coli O157:H7 strains that are listed in Table 1. These strains were also isolated from cattle faecal samples collected from eight (A, B, C, D, E, F, G, H) farms in the North-West province. These E. coli O157:H7 isolates were fully characterised and their virulent properties are outlined in a previous report [33]. A total of 14 E. coli O157:H7 strains were used as indicators to screen faecal samples for the presence of endemic phages. The selection was based on their genotypic variability as well the different geographical location from which the strains were isolated. E. coli O157:H7 strains were routinely grown in tryptic soy broth (TSB) broth at $37^{\circ} \mathrm{C}$ and preserved at $-80{ }^{\circ} \mathrm{C}$ in $20 \%$ (v/v) glycerol. During experimental procedures, bacterial stocks were held at room temperature for 1 hour and later sub-cultured on tryptic soy agar (TSA). Pure colonies were used as host strains for phage experiments.

Table 1: E. coli O157:H7 strains used in the detection of phages and their sources from which they were isolated 


\begin{tabular}{|l|l|l|}
\hline \multirow{2}{*}{ Farm/Source } & Strain ID & PFGE group \\
\hline \multirow{2}{*}{ A } & A27 & VI \\
\cline { 2 - 3 } & A40 & I \\
\hline \multirow{2}{*}{ B } & B10 & IV \\
\hline & B56 & IV \\
\hline E & C9 & V \\
\hline \multirow{2}{*}{ F } & C13 & I \\
\hline \multirow{2}{*}{ G } & E7 & VI \\
\hline \multirow{2}{*}{ H } & E13 & V \\
\hline & F1 & V \\
\hline & F5 & V \\
\hline
\end{tabular}

\subsection{Ethical clearance}

This study was approved by the Mafikeng Campus Animal Ethics Committee of the North West University, South Africa and ethical clearance (NWU-00074-15-A9) was issued prior to sample collection.

\subsection{Enrichment and isolation of bacteriophages with $E$. coli $\mathrm{O} 157: \mathrm{H} 7$ as the host}

The isolation and enrichment of phages was based on a previously described method [34] with modifications. Cattle faecal samples were collected between May 2017 to August 2017 from cattle in farms in North West province, South Africa and used as bacteria host strains for phage isolation. Ten grams of faecal samples was dissolved in $100 \mathrm{ml}$ of lambda dilute and mixed thoroughly. Faecal suspensions were centrifuged at $10000 \mathrm{xg}$ for $10 \mathrm{mins}$ to remove particulate matter. The clarified sample $(10 \mathrm{ml})$ was added to a $10 \mathrm{ml}$ overnight culture of each of 14 E. coli O157:H7 host strains in double-strength TSB with $2 \mathrm{mM} \mathrm{CaCl}$. The suspension was incubated for $48 \mathrm{~h}$ with gentle shaking at $50 \mathrm{rpm}$ at $37^{\circ} \mathrm{C}$. After incubation, suspension were centrifuged at $5,400 \times \mathrm{g}$ for $15 \mathrm{~min}$ at $4{ }^{\circ} \mathrm{C}$ and supernatants were carefully filtered through $0.22 \mu \mathrm{m}$ Millipore syringe filters (Fischer Scientific, Ottawa, ON) and the clarified crude lysates (filtrates) were stored at $4{ }^{\circ} \mathrm{C}$.

The spot-test technique was used to detect for phage activity against E. coli O157:H7 [35]. Briefly, $100 \mu \mathrm{l}$ of an overnight culture of the bacterial hosts were mixed with $3 \mathrm{ml}$ of molten top agar $(0.6 \%$ $\mathrm{w} / \mathrm{v}$ agar) held at $50{ }^{\circ} \mathrm{C}$ and then overlaid immediately unto Modified nutrient agar (MNA) agar plates so as to create a bacterial lawn and allowed to solidify for 15 mins. Phage activity was tested in the enriched samples by spotting with $10 \mu \mathrm{l}$ from each lysate on the top of soft agar containing the bacterial lawn and allowed to adsorb for about $10 \mathrm{~min}$. Plates were incubated at $37^{\circ} \mathrm{C}$ for $24 \mathrm{~h}$. After incubation, plates were observed for zones of cell killing or bacteria growth inhibition in the bacterial lawns at the sites where the lysate was dropped. If present, the cleared spots were collected from the overlays (soft-agar layers) by cutting using a one $\mathrm{ml}$ pipette tip and placing each plaque individually in a $2 \mathrm{ml}$ Eppendorf tube containing $300 \mu \mathrm{l}$ of phage buffer. The tubes were stored overnight at room temperature to allow phage particles to diffuse out from the soft agar. The mixture was later filtered through $0.22 \mu \mathrm{m}$ Millipore syringe filters (Fischer Scientific, Ottawa, ON) membrane syringe filters. 


\subsection{Purification of phages}

Isolated phages were purified using the soft agar overlay method described by [35]. Ten-fold serial dilutions of each lysate that was positive for the spot test was prepared, and $100 \mu \mathrm{l}$ of each dilution was mixed with $100 \mu \mathrm{l}$ of an overnight culture of the host bacterium for $10-15$ mins at $30^{\circ} \mathrm{C}$. Three millilitres of molten top agar held at $50{ }^{\circ} \mathrm{C}$ was added to the mixture and overlaid onto MNA agar plates. Plates were incubated at $37^{\circ} \mathrm{C}$ for $16-24 \mathrm{~h}$ in upright positions. Plaques from different bacteria hosts with varying sizes and morphologies were picked from the overlays and placed individually in $300 \mu \mathrm{l}$ phage buffer $\left\{\lambda\right.$-buffer: $5.8 \mathrm{~g} / \mathrm{L} \mathrm{NaCl} ; 2 \mathrm{~g} / \mathrm{L} \mathrm{MgSO}_{4} .7 \mathrm{H}_{2} \mathrm{O} ; 10 \mathrm{ml} / \mathrm{L} 1 \mathrm{M}$ Tris$\mathrm{HCl}$ (pH7.5)\} and held overnight incubation at $4{ }^{\circ} \mathrm{C}$ for phages to diffuse out of the agar. Bacteriophages in the lysates were purified three successive times in order to obtain single plaques with homogeneous plaque morphologies. Ten-fold serial dilutions of the purified phage lysates were prepared and phages titres were determined and tested using the soft agar overlay technique. The purified phage lysates were stored at $4{ }^{\circ} \mathrm{C}$.

\subsection{Determination of the lysis profile of isolated phages}

The isolated bacteriophages were screened for their ability to infect host bacterial cells in order to determine their infectivity range or lysis efficiency. This assay is based on the ability of the phage to either produce a clear plaque, turbid plaque or no lysis against a specific host cell. , and A total of 69 environmental E. coli O157:H7 strains previously isolated from cattle and identified were used in this assay that employed the spot test [36]. Bacterial lawns of all the 69 E. coli O157:H7 strains were prepared on modified nutrient agar (MNA) and $10 \mu \mathrm{l}$ droplets of phages lysates with titres of $1 \times 10^{7}$ $\mathrm{PFU} / \mathrm{ml}$ were spotted on these lawns. The plates were incubated at $37^{\circ} \mathrm{C}$ for $24 \mathrm{~h}$ and checked for the presence of plaques. The most efficient phages based on the lysis profiles, plaque clarity and size thus displaying zones of lysis against most of the isolates were selected for further studies.

\subsection{Propagation of phage in liquid medium}

Phage propagation was performed using the liquid propagation method [35]. Briefly, for each phage, $1 \mathrm{ml}$ of the mid-exponential phase $\left(\mathrm{OD}_{600}=0.45-0.55\right)$ culture of the host bacterium was inoculated to $100 \mathrm{ml}$ of fresh modified tryptic soy broth (mTSB) containing $10 \mathrm{mM} \mathrm{CaCl}$. To this $100 \mu \mathrm{l}$ of phage lysate with at least $1 \times 10^{8} \mathrm{pfu} / \mathrm{ml}(\mathrm{MOI} \sim 0.1)$ was added and incubated aerobically at $37^{\circ} \mathrm{C}$ with shaking at $170 \mathrm{rpm}$ for $6-8 \mathrm{~h}$ or until lysis occurred. The mixture was centrifuged at $6000 \mathrm{xg}$ for 10 mins at $4{ }^{\circ} \mathrm{C}$. The supernatant was neutralized with $0.1 \mathrm{~N} \mathrm{NaOH}(\mathrm{pH}=7.0)$ and filtered with $0.2 \mu \mathrm{m}$ syringe filter (Fischer Scientific, Ottawa, ON). The titres of phages present in the lysate was determined using the double layer agar method (34). Aliquots of $100 \mu \mathrm{l}$ from each 10 -fold serially diluted lysate was mixed with $100 \mu \mathrm{l}$ of the bacterial host suspensions and $3 \mathrm{ml}$ of $0.6 \%$ (w/v) top agar was added to the tubes. The contents of the tubes were immediately poured unto Modified nutrient agar (MNA) agar plates and plates were allowed to solidify for 15 mins. Plates were incubated aerobically at $37^{\circ} \mathrm{C}$ for $24 \mathrm{~h}$. Phage titration was done in triplicate. High titre phage lysates were stored at $4{ }^{\circ} \mathrm{C}$ until they were concentrated using PEG.

\subsection{Concentration and Purification with Polythethylene Glycol (PEG)}

Phage concentration and purification was performed using a previously described methods [37, 38]. DNAse 1 and RNAse A to a final concentrations of $1 \mu \mathrm{g} / \mathrm{ml}$ respectively were added to lysates to 
degrade residual bacterial DNA and RNA while $0.5 \mathrm{M} \mathrm{NaCl}$ was later added to the mixture and incubated at $40^{\circ} \mathrm{C}$ for $1 \mathrm{~h}$. The suspension was centrifuged at $6000 \mathrm{xg}$ for $10 \mathrm{~min}$ at $4{ }^{\circ} \mathrm{C}$ and the phage-containing supernatant was transferred into a clean flask. High titre propagated phage lysates were precipitated by adding PEG 8000 gradually with constant stirring, to a final concentration of $10 \% \mathrm{w} / \mathrm{v}$. The mixture was incubated at $4{ }^{\circ} \mathrm{C}$ overnight to allow precipitation of the phage particles. A PEG pellet, containing phage particles, was obtained by centrifugation at 11,000 $x \mathrm{~g}$ for $10 \mathrm{mins}$ and at $4{ }^{\circ} \mathrm{C}$. Supernatants were carefully removed using a pipette and care was taken to ensure that the pellet was undisturbed. The pellet was washed twice in $0.1 \mathrm{M}$ ammonium acetate $(\mathrm{pH}=7.0)$ and resuspended in $0.5 \mathrm{ml}$ sterile distilled water. The re-suspended pellet was incubated overnight at $4{ }^{\circ} \mathrm{C}$ in order to soften it. The phage suspension was stored at $4{ }^{\circ} \mathrm{C}$ until transmission electron microscopy.

\subsection{Transmission Electron Microscopy}

The morphology of the isolated phages was investigated using the transmission electron microscope [38]. Sample preparation and electron microscopy was performed by Dr. Anine at the North-West University, Potchefstroom Campus in South Africa. Briefly, phage pellet obtained after PEG precipitation and ammonium acetate washing was re-suspended in $50 \mu \mathrm{l}$ lamda diluent. A drop of the suspension was placed on carbon-coated formvar grids and allowed to stand for $2 \mathrm{~min}$. The suspension was stained with $1 \%(\mathrm{w} / \mathrm{v})$ ammonium molybdate $(\mathrm{pH}=7.0)$ for $5 \mathrm{~min}$ and excess fluid was drawn off with filter paper. Grids were allowed to air dry and then examined with a FEI Tecnai G2 20 S-Twin transmission electron microscope operating at $120 \mathrm{kV}$ and a magnification range of 20000 - 100000. Micrographs were taken with a Gatan bottom mount camera using Digital Micrograph software at $80 \mathrm{kV}$ and a magnification range of 20,000 to 250,000.

\subsection{Phage stability under different chemical and physical conditions}

\subsubsection{Effect of different incubation temperatures on phage stability}

To determine the effects of different incubation temperatures on phage stability, phage lysates of known titres were incubated at $45^{\circ} \mathrm{C}$. Titre of the phage was determined by the soft-agar overlay technique after $1 \mathrm{~h}$ incubation. The experiment was repeated at temperatures $50^{\circ} \mathrm{C}, 55^{\circ} \mathrm{C}$ and $60^{\circ} \mathrm{C}$. Phages that were diluted in phage buffer was used as a control. Each treatment was performed in triplicate. The inoculated plates were incubated at $37^{\circ} \mathrm{C}$ for $24 \mathrm{~h}$ and after $24 \mathrm{~h}$ the number of plaques was counted for each treatment and results were recorded.

\subsubsection{Effect of different $\mathrm{pH}$ levels on phage stability}

The $\mathrm{pH}$ stability of the phage was determined using a previously described method with some modifications [39]. Briefly the $\mathrm{pH}$ of TSB was adjusted to the following ranges: 2, 4, 8, 10, and 12 by the addition of either $1 \mathrm{M} \mathrm{HCL}$ or $1 \mathrm{M} \mathrm{NaOH}$. Aliquots of $900 \mu \mathrm{l}$ of the $\mathrm{pH}$ adjusted TSB were transferred into Eppendorf tubes and $100 \mu \mathrm{l}$ of phage lysates were added to the tubes. The tubes were gently mixed and left to stand at room temperature for $18 \mathrm{~h}$. After $18 \mathrm{~h}$ the titre of the phages in each sample was determined using the soft agar overlay technique [35]. In order to achieve this, $100 \mu$ of phage suspension was mixed with $100 \mu \mathrm{l}$ of overnight culture, and the mixture plated using the double layer agar techniques. Phage diluted in TSB was used as a control. Each treatment was performed in triplicate. All plates were incubated aerobically at $37^{\circ} \mathrm{C}$ for $24 \mathrm{~h}$ and the number of plaques was counted to determine phage titre for each $\mathrm{pH}$ treatment and results were recorded. 


\subsubsection{Effect of salinity on phage stability}

The effect of different saline concentrations on the stability of the phages was determined [39]. Aliquots of $100 \mu \mathrm{l}$ of each phage lysate was added to $900 \mu \mathrm{l}$ of TSB containing $0.5 \%, 10 \%$ and $15 \%$ $\mathrm{NaCl}$ respectively and incubated aerobically at $37^{\circ} \mathrm{C}$ for $18 \mathrm{~h}$. Phage diluted in TSB was used as a negative control in the experiment. After incubation, both the treated and untreated phage lysates were plated using the soft-agar overlay technique. The number of plaques were counted and used to determine the phage titre for each of the different treatment and control samples.

\subsubsection{Effect of chloroform on phage stability}

The effect of chloroform on the stability of phages was determined using a previously described method but with minor modifications [39]. Optimal phage dilutions of $1 \times 10^{5}$ was prepared in lambda diluent. Aliquots of $1 \mathrm{ml}$ of each dilution was treated with $10 \%(\mathrm{v} / \mathrm{v})$ chloroform and stored at room temperature $\left(25^{\circ} \mathrm{C}\right)$ with gentle shaking for $1 \mathrm{hr}$. The suspension was centrifuged at $10000 \mathrm{x} g$ for 10 mins at $4{ }^{\circ} \mathrm{C}$. The phage titre of the supernatant was determined using an overnight culture of $E$. coli O157:H7 G17 as the host bacterium. A phage diluted in lambda diluent was used as acontrol sample. Treatments were performed in triplicates. Plates were incubated at $37^{\circ} \mathrm{C}$ for $24 \mathrm{~h}$ and phage titres were calculated using average values for each treatment.

\subsection{One-step growth curve}

Burst sizes and latent periods of selected phages were determined by a one-step growth experiment according to a previous method [40]. Phages were diluted in $9.9 \mathrm{ml}$ TSB in order to obtain $10^{6} \mathrm{pfu} / \mathrm{ml}$. The temperature of the diluted phage lysate and overnight culture was maintained at $37^{\circ} \mathrm{C}$ in a water bath. Phages were added to host bacterium at MOI of 0.1 and the mixture was mixed well and incubated at $37^{\circ} \mathrm{C}$ while noting the time 0 . Two large tubes containing $9.9 \mathrm{ml}$ of TSB were prepared for $10^{2}$ and $10^{4}$ dilutions and kept at $37^{\circ} \mathrm{C}$. After 10 mins of incubation, $100 \mu \mathrm{l}$ of the adsorption mixture was transferred into the $10^{2}$ tube and mixed thoroughly. Using a clear and sterile pipette, 0.1 $\mathrm{ml}$ of the mixture was transferred from the tube with dilution factor $10^{2}$ to tube $10^{4}$. The contents in the tube was mixed thoroughly and incubated at $37{ }^{\circ} \mathrm{C}$ for 90 mins. After 20 mins, samples were collected every 5 mins for $90 \mathrm{~min}$ and phages were titrated in each respective sample as previously described [40]. The relative burst size was determined by dividing the number of virus-like particles released from the cell by the number of virus particles initially added. The relative burst size obtained at different time intervals were plotted against time to determine the latent periods. The average counts obtained from triplicate treatments per sample, were plotted to obtain the one-step growth curve [40].

\subsection{Pulsed filed gel electrophoresis (PFGE) to determine bacteriophage genome size}

Phage genome size was determined by pulsed field gel electrophoresis (PFGE) using a previous method [35]. Briefly, $200 \mu \mathrm{l}$ of purified and concentrated phage suspension was mixed with $10 \mu \mathrm{l}$ of $20 \mathrm{mg} / \mathrm{ml}$ proteinase K (Sigma-Aldrich, USA) solution and $200 \mu \mathrm{l}$ of $1.2 \%$ (w/v) molten plug agarose (Bio-Rad, Hemel Hempstead, UK) in TE buffer. These contents were mixed properly and dispensed into plug molds (BIO-RAD, UK) and allowed to solidify. Solidified plugs were removed and placed in Eppendorf tubes containing $5 \mathrm{ml}$ of lysis solution [50 mM EDTA pH 8.0, $50 \mathrm{mM}$ Tris-HCI (pH 8.0), $1 \%(\mathrm{w} / \mathrm{v}$ ) sarcosyl and $25 \mu \mathrm{l}$ of $20 \mathrm{mg} / \mathrm{ml}$ proteinase K solution] all obtained from Sigma-Aldrich, UK. Each tube was incubated at $55^{\circ} \mathrm{C}$ for $2 \mathrm{~h}$ with constant and vigorous agitation at $175 \mathrm{rpm}$. The lysis 
solution was discarded and $5 \mathrm{ml}$ of warm sterile distilled water was added to each tube. The contents of the tubes were incubated at $55^{\circ} \mathrm{C}$ for $15 \mathrm{~min}$, then plugs were washed 3 times with TE buffer [ 20 mM Tris-HCI ( $\mathrm{pH} 8.0$ ), $50 \mathrm{mM}$ EDTA ( $\mathrm{pH} 8.0$ )] and incubated at $55^{\circ} \mathrm{C}$ for 15 mins between each wash. Each plug was cut into $3 \mathrm{~mm}$ slices, transferred to the wells of a $1 \%(\mathrm{w} / \mathrm{v})$ agarose (Bio-Rad, UK) gel prepared in 0.5 X TBE (Sigma-Aldrich, UK). Chromosomes isolated from Saccharomyces cerevisiae, strain YPH80 and supplied by Sigma, UK was included in each gel and used as a PFGE marker. The wells were sealed with molten $1 \%(\mathrm{w} / \mathrm{v})$ agarose and allowed to set, after which they were transferred to a Bio-Rad CHEF-DR® II electrophoresis system (Bio-Rad Laboratories, UK). Electrophoresis was performed in $0.5 \mathrm{X}$ TBE at $6 \mathrm{~V} / \mathrm{cm}$ for $18 \mathrm{~h}$ with incremental pulses of $2.2-54.2 \mathrm{~s}$ and with the buffer circulating at $14^{\circ} \mathrm{C}$. Gels were stained in $1 \mu \mathrm{g} / \mathrm{ml}$ of ethidium bromide for $30 \mathrm{~min}$ and images were captured with a ChemiDoc XRS Imager (Bio-Rad, UK) using the Quantity One program.

\subsection{Restriction Enzyme analysis of bacteriophage DNA}

The remaining bacteriophage genomes in agarose plugs previously prepared in the PFGE procedure were subjected to the Restriction Fragment Length Polymorphism (RFLP) protocol by digesting them with different restriction endonucleases obtained from Biolabs (New England Biolabs, UK). Restriction enzymes EcoRI, HindIII, SSPI and NDEI were used in the RFLP and the digestion was carried out according to the manufacturer's instruction. The reactions were incubated at $37^{\circ} \mathrm{C}$ for $16 \mathrm{~h}$. The plugs were then subjected to the PFGE using 16-18 h using a pulse time of $1 \mathrm{~s}-15 \mathrm{~s}$ and $6 \mathrm{~V} / \mathrm{s}$ alongside with Lamda PFGE marker. Restriction digestion banding patterns were compared visually.

\section{Results}

During this study, 152 cattle faecal materials were screened separately for the presence of bacteriophages using environmental E. coli O157:H7 strains as hosts. The presence of different bacteriophages specific to E. coli O157:H7 from 152 faecal samples collected from cattle farms in the North-West Province, South Africa, was detected using the spot test and double layer agar techniques. Of the 152 samples analysed, only 15 possessed phages that were active against the environmental E. coli O157:H7 strains. These 15 different phages were chosen for further purification, propagation and characterization. Details of phages isolated from the different farms are shown in Table 2.

Table 2: Isolation of E. coli O157:H7 bacteriophages

\begin{tabular}{llll}
\hline Farm & Total Sample & No. of phages detected & \\
\hline A & 25 & - & V1, V2V3, V4 \\
B & 47 & 4 & V5, V6, V7 \\
C & 50 & 3 & V8, V9, V10, V11, v12, v13V14, V25 \\
D & 30 & 6 & \\
Total & $\mathbf{1 5 2}$ & $\mathbf{1 5}$ & \\
\hline
\end{tabular}

Table 3: Morphological characteristics of the isolated phages

\begin{tabular}{lll}
\hline Phage & Plaque Morphology size $(\mathrm{mm})$ & Titre $(\mathrm{PFU} / \mathrm{ml})$ \\
\hline
\end{tabular}




\begin{tabular}{llll} 
V3 & Clear, small & 1.5 & $2 \times 10^{10}$ \\
V7 & Clear, medium & 2 & $2.5 \times 10^{8}$ \\
V8 & Clear, medium & 2 & $1 \times 10^{10}$ \\
\hline
\end{tabular}

\subsection{Lytic profile}

The lytic profile of the isolated phages was determined against a total of 69 different environmental E. coli O157:H7 strains that were previously obtained and characterized [33]. The results in Table 4 showed that a large proportion $(86.9 \%)$ of the environmental stains were resistant to phage activity since no plaques was formed when phages were spotted on the bacterial lawn. However, some of the phages demonstrated narrow host range and were able to produce areas of clear zones on bacterial lawn. Phages V6, V12, V13, V14 and V15 were each able to lyse only two bacterial hosts while phages V1, V2, V9, and V11 were able to lyse 3 E. coli O157:H7 strains. Contrary to the low levels of virulence displayed by these phages, three phages (V3, V7 and V8) demonstrated broadest spectrum of activity since they could infected between 7 and 10 E. coli O157:H7 host strains. These three super-phages were selected for further characterisation.

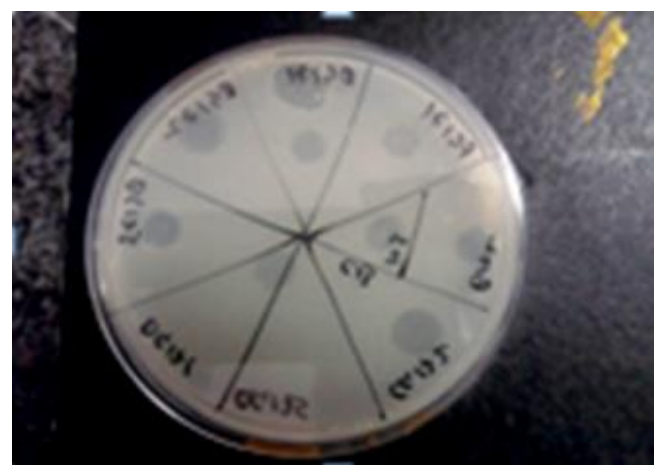

Fig 1: Plaque assay of phage lysates spotted on a bacterial lawn of E. coli O157 PhiG17 as indicator strain.

Table 4: Lytic effect of phages on E. coli O157 strains. 

H1, H4, H5 and H12 were lysed by only one phage while B17, C9, H2, and H6 were each lysed by 2 or more different phages. E. coli O157 strains C13 and G17 exhibited the highest level of susceptibility to the phages and were lysed by 9 and 15 phages respectively.

\subsection{Characterisation of selected phages}

\subsubsection{Morphology of Phage}

Transmission electron microscopy (TEM) of the phages displayed morphologically similar structures. All the obtained phages have icosahedral heads and short non-contractile tails with tail fibres (Fig 2). Based on these morphological characteristics, these phages were assigned to the family Podoviridae according to the classification system of Ackermann [41]. The diameters of the capsids of V3, V7 and V8 were $75 \pm 3.6 \mathrm{~nm}, 73 \pm 1.2 \mathrm{~nm}$, and $77 \pm 3.1 \mathrm{~nm}$ respectively. The tail of $\mathrm{V} 3$ had a length of $23 \pm 3.1 \mathrm{~nm}$, V7 $-25 \pm 3.2 \mathrm{~nm}$ and V8 was $20 \pm 1.0 \mathrm{~nm}$. 


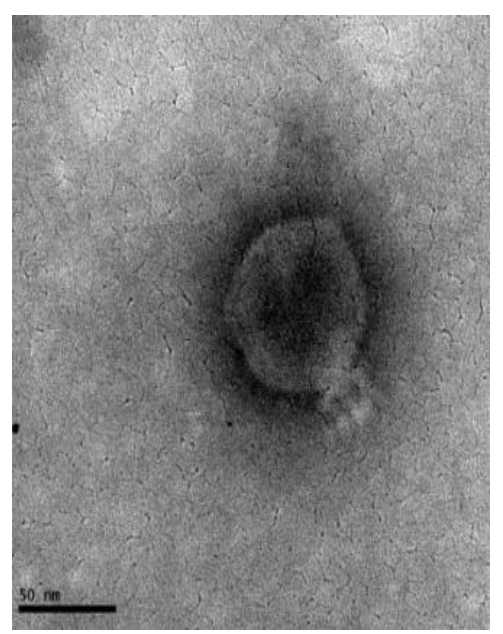

A

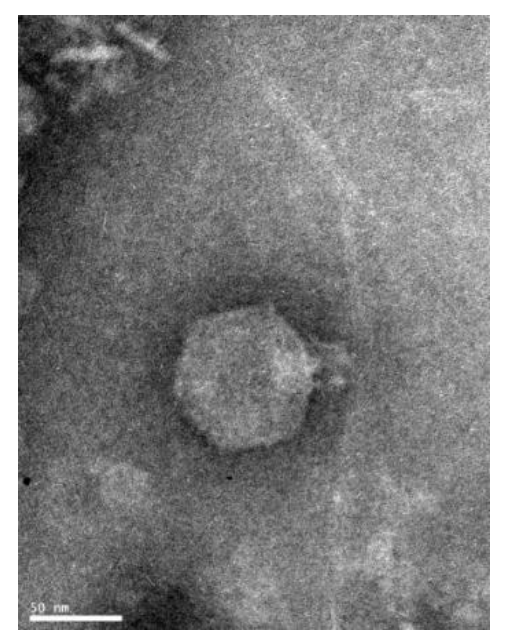

B

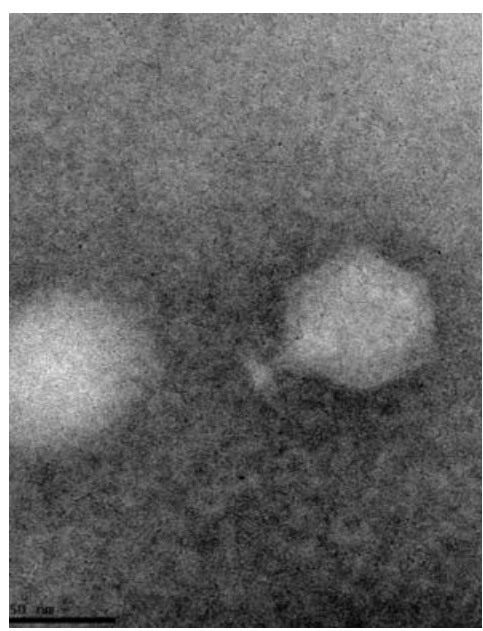

C

Fig 2: Electron micrographs of E. coli O157:H7 phages. Bar = 50 nm. (A) V3, (B) V7, (C) V8

\subsection{Phage growth characteristics}

The single- step growth curve for the determination of the latent periods the time interval between the adsorption and the beginning of burst and burst size for the 3 phages is represented in figure 3. Phage V8 had the highest burst size of 419 phages per infected cell among the 3 phages with a latent period of $20 \mathrm{~min}$, this was followed by V3 that had a burst size of 374 phages per infected cell with the same latent period as phage V8 (20min). But phage V7 had the lowest burst size of 349 phages per infected cell with a latent period of $15 \mathrm{~min}$.

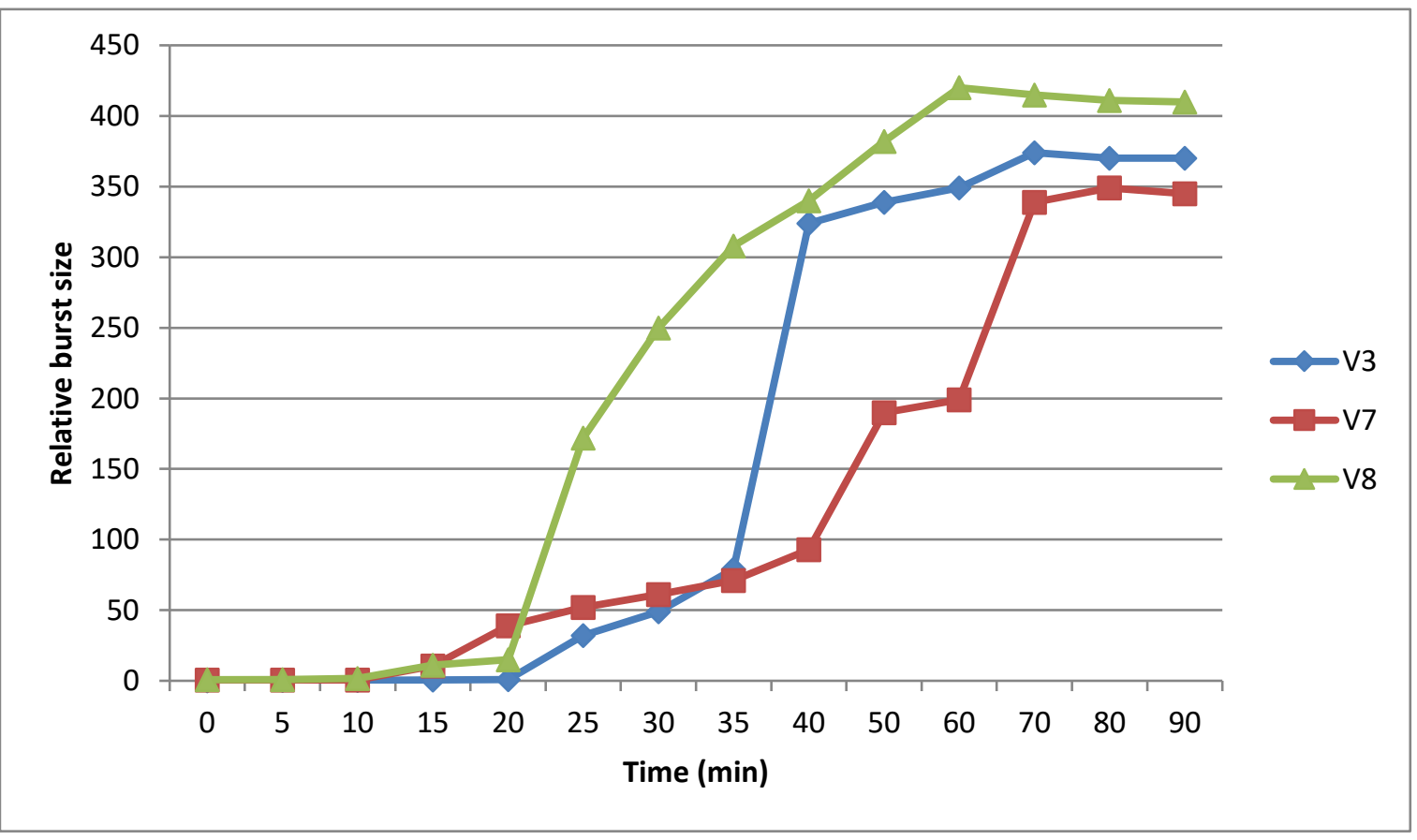

Fig 3: One-step growth curve of phages V3, V7 \& V7 


\subsection{Phage stability under different chemical and physical conditions}

\subsubsection{Temperature}

Results showed that decreasing the incubation temperature resulted in an increase in phage titres particularly at temperatures below $60{ }^{\circ} \mathrm{C}$ (Fig 4). It was evident that $55{ }^{\circ} \mathrm{C}$ was the optimum temperature for $\mathrm{V} 3$ phage replication while phage $\mathrm{V} 7$ was most stable at $45^{\circ} \mathrm{C}$ with just $20 \%$ reduction in titre and that there was a drop in titres at temperatures above $60^{\circ} \mathrm{C}$. Exposure to temperatures above $55^{\circ} \mathrm{C}$ was the most damaging with a great reduction (100\%) in phage titres for phage V7 and V8 while V3 was the most thermal stable among the phages with lowest reduction in titre even at $55 / 60^{\circ} \mathrm{C}$. Overall results showed that propagation of these phages is negatively affected by increased exposure to high temperatures.

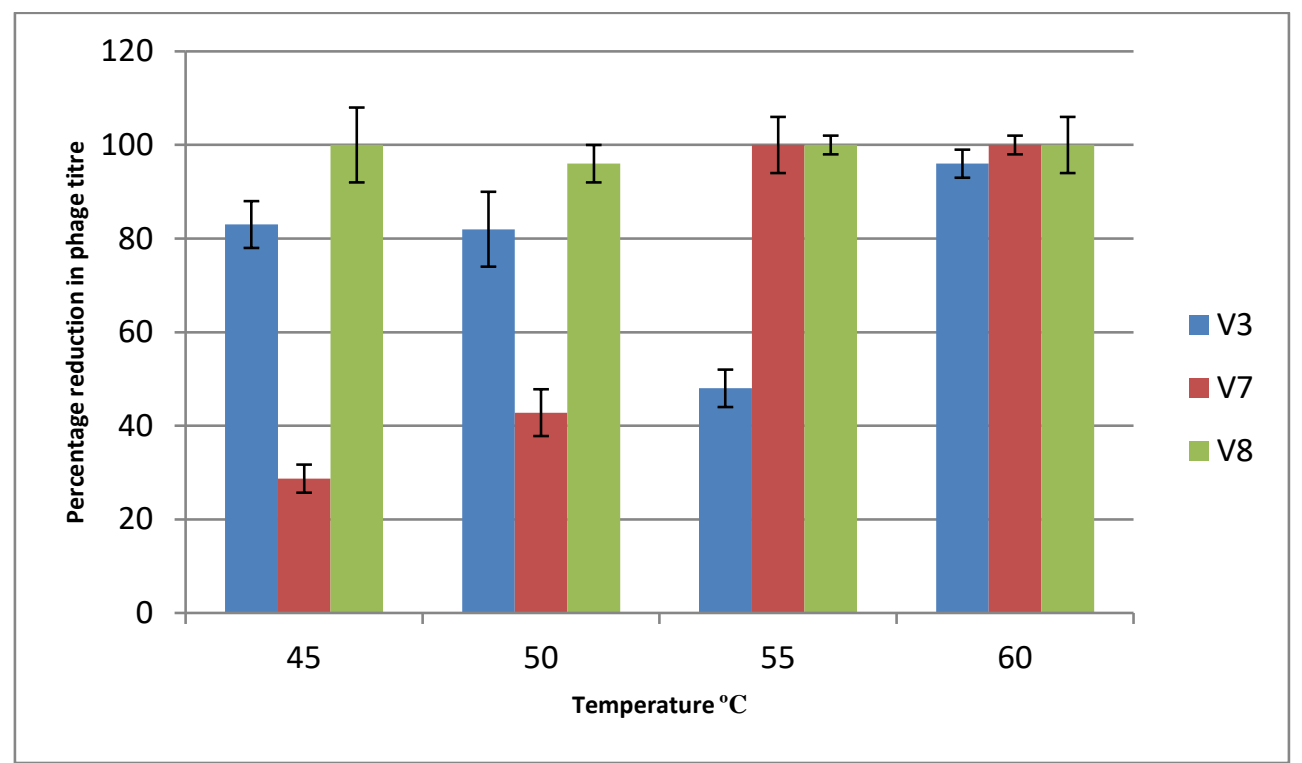

Fig 4: Thermal stability of the isolated phages. Error bars indicate standard deviation among the triplicate samples

\subsubsection{Ph}

The effect of the $\mathrm{pH}$ of the medium on the stability of phages was determined by suspending phage in $\mathrm{pH}$ adjusted TSB medium and percentage reduction in phage titre determined. Overall, most of the phages were more sensitive to acidic than alkaline conditions. Phage particles showed great stability within the $\mathrm{pH}$ range of 8.0 to 10.0 while a considerable decrease in titres observed at $\mathrm{pH}$ values below 6.0 and above 10.0. Phages V7 and V8 displayed similar $\mathrm{pH}$ stability but phage V3 was the least stable with a huge drop in the titre even at $\mathrm{pH} 6$ and 8. At pH 2, 4 and 12 100\% inactivation of the 3 phages was observed. 


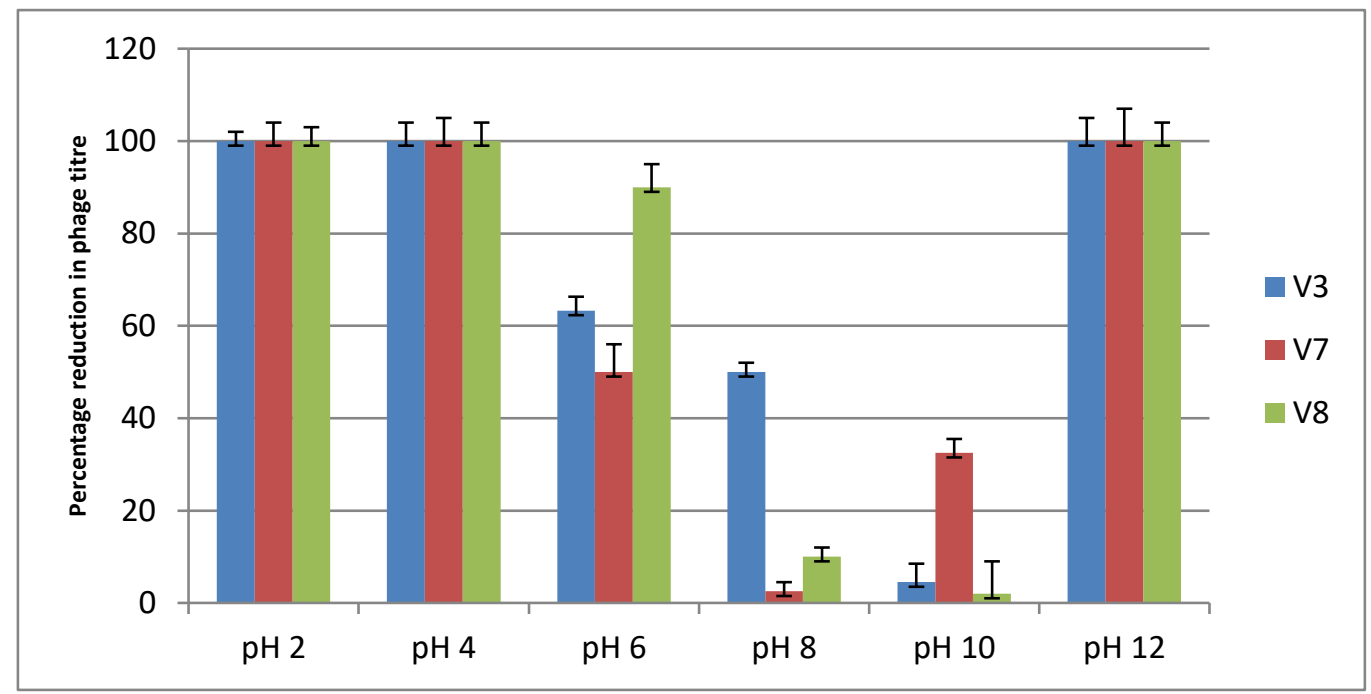

Fig 5: $\mathrm{pH}$ stability of the isolated phages

\subsubsection{Salinity}

All the three phages showed similar activity to the different salt concentration tested. Phages retained stability in the presence of $0.5 \% \mathrm{NaCl}$ with less than $20 \%$ reduction in titres. Similar stability was displayed by phages V3 and V8 in the presence of $5 \% \mathrm{NaCl}$ while phage V7 lost over $60 \%$ activity. In $10 \% \mathrm{NaCl}$, titres of the three phages were reduced by over $60 \%$. Surprisingly, all the tested phages survived exposure to $15 \% \mathrm{NaCl}$ albeit at a greater loss of activity.

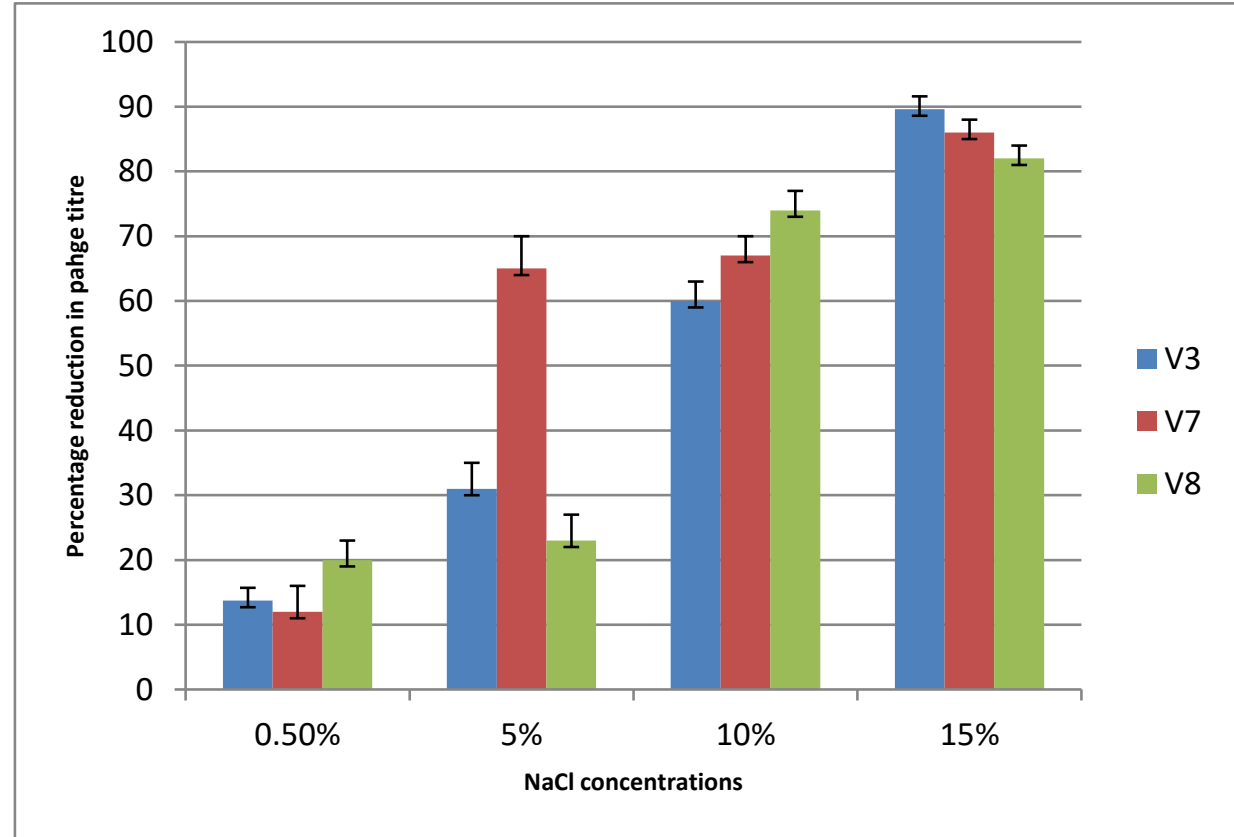

isolated phages under different $\mathrm{NaCl}$ concentrations

Fig 6: Stability of the

\subsubsection{Chloroform}

Chloroform exposure did not have negative impact on phage titres of V3 and V7. They remained stable in $10 \%$ chloroform after incubation for $1 \mathrm{~h}$. However, the addition of chloroform resulted in $40 \%$ reduction in phage titre of $\mathrm{V} 8$. 


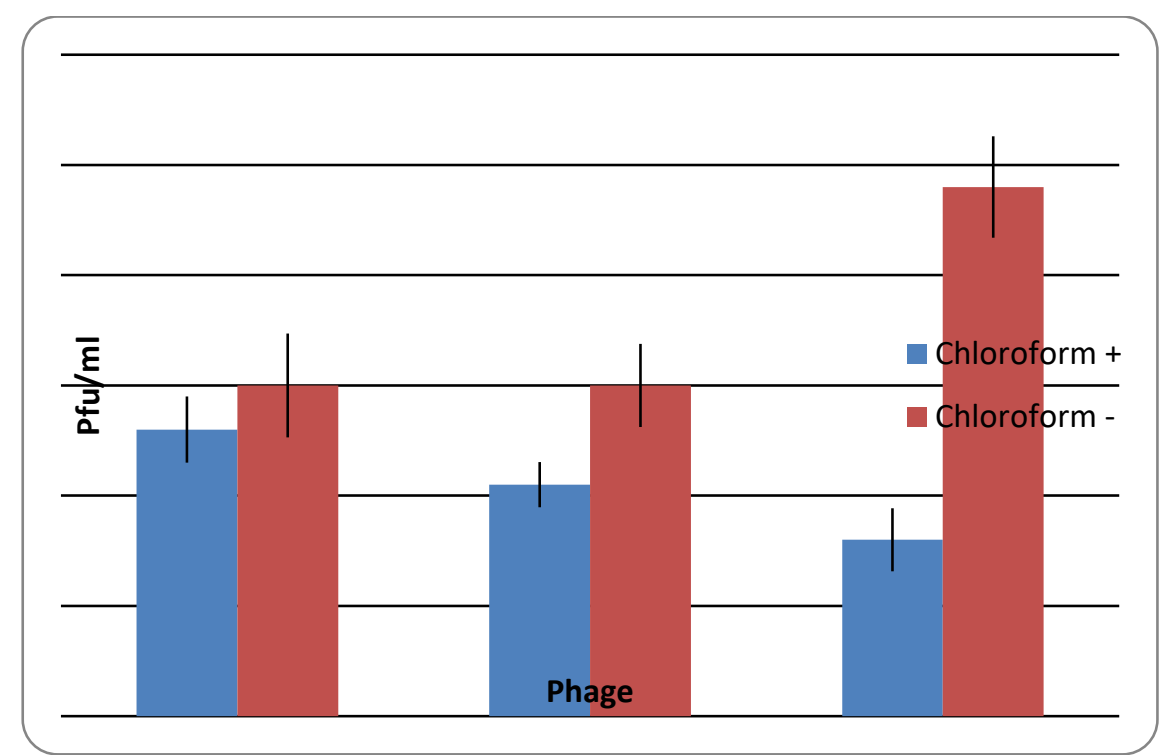

Fig 7: Effect of chloroform on the stability of the isolated phages

\subsection{Genomic characteristics}

\subsubsection{PFGE determination of phage genome size}

To estimate the genomic sizes of newly isolated phages V3, V7, V8, the phage samples were prepared in agarose plugs for PFGE and subsequent to electrophoresis the gels were stained with ethidium bromide and the images capture with a ChemiDoc XRS Imager using the Quantity one program (BioRad). Gels showed that phages contained a discreet single DNA band indicating that the purity of the phage stock and the band corresponding to the genomes of these phages. Using image genome DNA software, the genome sizes of the newly isolated phages were estimated to be $\sim 69 \mathrm{~Kb}$. 


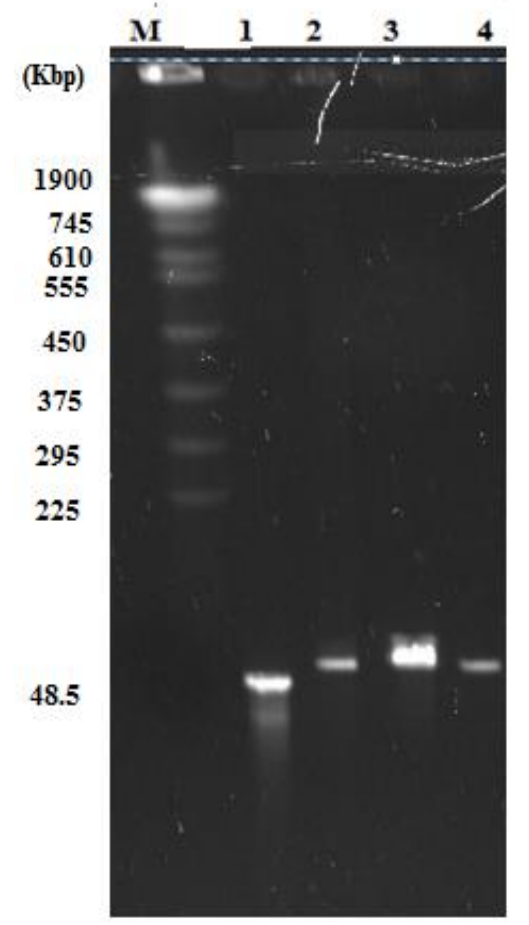

Fig 8: PFGE of phages prepared in agarose plugs without DNA extraction. Lane M: Yeast DNA Marker, Lane 1: uncut lambda; lane 2: V3, Lane 3: V7, Lane 4: V8

\subsubsection{Restriction endonuclease pattern}

The phages in agarose plugs were digested in-situ with different restriction endonucleases. Agarose electrophoresis on $1 \%$ gels of the digested DNA indicated that the phages had double stranded DNA, and the enzymes SspI and NdeI produced the best digestion patterns (Fig 9). Enzymes HindIII, and EcoRI had no restriction sites on the phage DNA (data not shown). The restriction enzymes SspI and $N d e I$ could not differentiate the phages based on banding patterns as similar patterns were observed in all of them, nevertheless the host range analysis and TEM analysis revealed subtle differences among them. Moreover the phages were obtained from different farms in the province. 


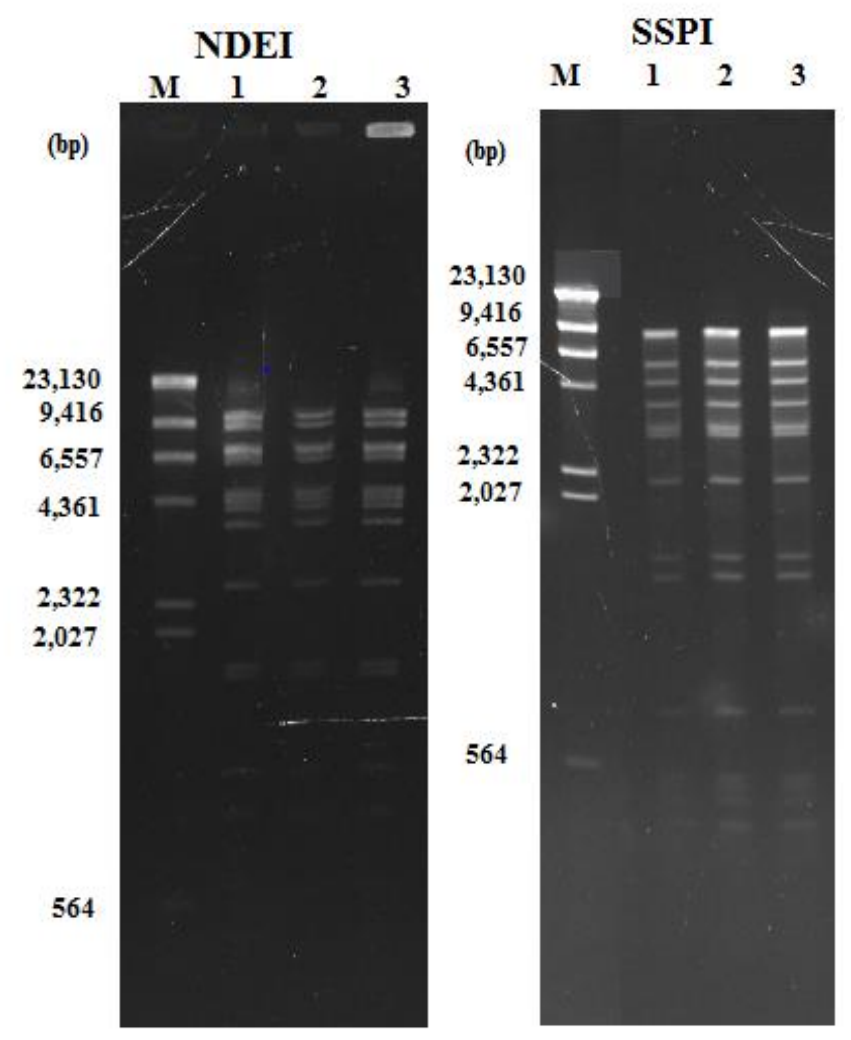

Fig 9: Restriction digestion of phage using $S s p I$ and NdeI. M= marker; Lanes 1, 2, $3=$ V3, V7, V8 respectively

\section{Discussion}

Bacteriophages have emerged as novel biotechnological tools that could be exploited in the control of foodborne pathogens such as E. coli O157:H7 [42-44]. Key to the successful application of phages in food safety is ensuring that potential candidates are strong, stable and strictly lytic against the targeted pathogens. Therefore newly isolated phages are screened and made to undergo a variety of phenotypic and genotypic characterisation so as to ensure that they meet these requirements.

In this study, the main objective was to isolate and propagate virulent phages against E. coli O157:H7 so that they could be characterised in terms of biological and physical properties that can be exploited for biocontrol purposes. For that purpose, cattle faecal material where the target bacteria are believed to be in abundance was used as a source for isolation of phages specific to E. coli O157:H7 [25, 45]. Overall, 15 lytic E. coli O157:H7 phages designated V1 to V15 were successfully isolated from the 152 processed faecal samples using environmental host strains. These phages were selected based on their ability to form a clear zone of lysis (plaques) on bacterial lawn since this suggested that they were virulent as these are preferred in biocontrol applications. The host strains were previously characterised in another study and selected after phenotypic and genetic characterisation to ascertain their diversity. The isolation rate of the phages in this study was relatively low in comparison to other studies that have reported high levels of E. coli phages in cattle faeces [28, 46]. One plausible explanation might be that there was low number/concentration of the host strains in the faecal samples resulting in greatly reduced chances of phage detection, for the prevalence of phage is dependent on host density threshold $[25,47]$. This possibility is further affirmed by the fact that different samples were sourced for the isolation of the host strains and the phage because both isolations could not be done concurrently and therefore the occurrence of E. coli O157:H7 in the phage 
isolation samples was unknown in this study. Studies have previously described the isolation of lytic phages against pathogenic E. coli O157:H7 from different sources such as sewage, cattle faeces and environmental samples all over the world [25, 26, 29, 48, 49] and hence demonstrated their abundance in nature. However, to the best of our knowledge, this is the first reported isolation and characterisation of virulent phages against E. coli O157:H7 in South Africa/ Africa.

The lytic spectra of a phage, which can be described as one of the most significant biological characteristics of a phage, is defined by what bacteria genera, species and strains it can kill [50]. In the biocontrol applications of phages, it is important that phage candidate which are virulent with broad lytic spectra are selected for instead of temperate and those with narrow lytic activity [36, 43]. This is due to the ability of temperate phages to transfer virulence or antibiotic resistance genes [51, 52] and narrowly lytic ones to be unable to cover many bacterial strains. The lytic profiles of the phages in this study were to some extent distinguishable from each other when different host strains of environmental E. coli O157:H7 were used, indicating the diversity among the phages. The lytic spectra of the phages however, would be considered relatively narrow since out of the 69 environmental host strains that were screened against, only 7 to 10 strains were lysed consistently by 3 of the 15 phages. Phages with narrow host range have been also been widely isolated against $E$. coli [53] and other species of bacteria including the lytic phage of Achrombacter - phiAxp-3 [54], Salmonella infecting phage P7 [55] FGSSA 2 [56] and N4-like Pseudomonas infecting phages [57]. Narrow spectrum of activity against bacteria host has been reported as a unique characteristic common to the N4-like phages [53]. The newly isolated phages are not only similar to the N4-like phages in terms of their host range; they also displayed morphological resemblance, suggesting possible relatedness to this group of phages.

Bacteria strains C13, E2 and G17 were the most susceptible, but a significant proportion of the bacterial strains were resistant. The differences in susceptibility of the bacterial strains could be due to various host factors/mechanisms that bacterial have employed to overcome the infection and killing action of phages. One such mechanism is losing phage receptor from bacterial surface. Phage attachment to a specific receptor on bacterial surface is the first essential step in phage infection and any change in the surface profile either by regulated expression or mutation in the receptors will result in phage insensitivity [58]. Another host factor contributing to the bacterial resistance is the presence of restriction endonucleases in some bacterial cells. These restriction systems act by degrading foreign viral DNA with subsequent obstruction to phage replication process. A further possibility but in this case not related to host factor is if the bacterial host strains are infected with temperate phages that renders them lysogens and confer lysogenic immunity. Such lysogenized bacteria will be immune to super-infection by a related phage. In this study it appeared that most of the bacteria strains employed in lytic profile assay could have possessed any of the resistance mechanisms and thus the wide resistance displayed by them. However, despite the observed bacterial resistance and the consequential narrow host range of the phages, they are not totally useless because they can still be used in developing phage cocktails so as to increase the breath of bacteria strains that they can control. Three of the phages (V3, V7, and V8) though demonstrated moderate capability to lyse environmental strains of E. coli O157:H7 had a much broader lytic profile among the isolated phages and were selected for further characterisation.

The TEM analysis that is comparable to Gram-staining in bacteriology is the fastest and easiest characterisation method that aids in the attribution of phages to families and for the identification of novel phages $[59,60]$. Observation under TEM revealed that all the 3 phages despite being isolated 
from different samples/farms belonged to the family Podoviridae which is characterised by icosahedral head and short non contractile tails. This family is one of the three main families of the Caudovirales otherwise referred to as the tailed phages. Although earlier studies have demonstrated that the tailed phages (Caudovirales) represents the most diverse, numerous and wide spread of all bacterial viruses, the Podoviridae family are the least represented accounting for about $14 \%$ of this group [61, 62]. Similarly, more recent studies investigating the morphology of environmental E. coli O157:H7 bacteriophages have supported the dominance of the other two families - Myoviridae and Siphoviridae $[27,63,64]$. This evidence indicates that E. coli O157:H7 infecting Podoviridae are uncommon in the studied environment and the isolation of this rare group in the present study could improve our knowledge and understanding of them prior to biocontrol application.

The phages were further characterised when the one step growth experiment was employed in determining/define the infection characteristics such as the latent period and burst size that can be explored to check the efficiency of a phage's ability to infect and develop in a particular host. The burst sizes of the phages were 374, 349 and 419 particles per cell, with an average latent period of 15 min for V8 and 20 min for V3 and V7. Seven E. coli O157 - phage infecting also demonstrated short latent periods ranging from 12 to $30 \mathrm{~min}$ and large burst sizes between 89- 631 particle per cell [49]. Conversely, the burst sizes of the isolated phages in this study are considered large when compared to other E. coli phages where average burst size as small as 33 and $51 \mathrm{pfu} / \mathrm{cell}$ have been reported [65]. On the other hand, a burst size of 9000 pfu/cell has been reported for a Podovirus- phage phiAxp-3 [54]. Variations in latent period and burst size of different phages could be attributed to the differences in host cells, growth medium, $\mathrm{pH}$ and temperature of incubation [66]. The relatively short latent period and large burst size of phage V3, V7 and V8 suggested they have a selective advantage over other competing phages whereby they could produce enough virions within a short time to lyse the host bacteria. Therefore phages V3, V7, V8 obtained in this study possessed outstanding characteristics regarding their short latent periods (15-20min) and large bust sizes which make them attractive candidates for a biocontrol treatment program.

In addition to characterisation based on biological properties, newly isolated phages should be assessed for their stability and persistence when exposed to different external conditions that they might encounter in the environment so as to confirm their biocontrol potential [43]. Thus a further objective of the study was to investigate the response of the 3 phages to changes in physico-chemical stress factors that might be experienced during production of phage or during biocontrol application of formulated phages. The 3 phages showed almost similar behaviour and stability at different incubation temperatures and $\mathrm{pH}$. They were stable between $45^{\circ} \mathrm{C}$ and $55^{\circ} \mathrm{C}$ for 60 mins, however temperatures above $55^{\circ} \mathrm{C}$ resulted in the reduction of the titres, which might be due to the effect of these high temperatures on phage proteins [67]. Studies investigating the effect of temperature on phage stability have reported similar observation [49] of the ability of some phage to withstand high temperatures. The thermal stability of the phages to high temperature $\left(45^{\circ} \mathrm{C}-55^{\circ} \mathrm{C}\right)$ in this study suggested that they could be suitable for application on carcasses/meat of the phages particularly at the post-harvest stage in combination with other food processing technologies involving thermal treatments to improve microbial safety of food.

Acidic environments affect the infectivity of E. coli phages and it was suggested that these conditions result in denaturation of phage proteins and consequently loss of phage viability [68]. Earlier research have reported that most tailed phages are stable at pH 5.0 to $9.0[69,70]$ and this was consistent with the results obtained in this study. While all of the isolated phages were highly 
sensitive to overnight exposure to acidic ( $\mathrm{pH} 2.0$ and $\mathrm{pH} 4.0$ ), some phages especially phage V3 were found to be resistant to a higher alkaline environment ( $\mathrm{pH} 10.0$ ). This was similar to previous reports on the preference of Podoviruses for alkaline conditions and their sensitivity to acidic conditions [71] This alkaline stability would consequently increase the area of application of these phages.

The isolated phages were also tested for their stability to varying salt $(\mathrm{NaCl})$ concentrations. Since some meat processing procedures require the incorporation of salt either as flavour enhancers or preservatives. The isolated phages showed high stability in low salt concentration $(0.5-5 \%)$. But increasing the concentration $(10 \%-15 \%)$ led to a greater reduction in phage activity. The observed saline stability is in agreement with studies conducted by some researchers where high levels of salt, in some cases up to $5 \mathrm{M}$ did not affect the phage titre [63, 70]. The adverse effect of increasing salt concentration can be due to osmotic pressure exerted on phage capsids preventing the ejection of phage DNA [72] or aggregating effect of high salt concentration on phage particles with concomitant reduction in bacterial binding sites. The ability of these phages to withstand high salt concentration is indicative of the possibility of applications in high-salt meat products that might be infected with E. coli O157:H7.

During the isolation, purification and preparation of phages, certain chemicals such chloroform are incorporated into the growth medium to enhance lysis and also included in the phage lysates to prevent bacterial contamination [35]. The isolated phages showed a high level of stability to chloroform treatment after $2 \mathrm{~h}$. Thus the incorporation of $10 \%$ chloroform into the phage medium during isolation and storage is recommended for these phages. However, in this study, chloroform was not used when the sensitivity to this agent was unknown. Some authors have reported varying results on the susceptibility of phages to chloroform and suggested that the sensitivity of each phage is confirmed prior to chloroform treatment ().

In order to further characterise the phages, their genomic properties were studied. Firstly, the sizes of the genomes were determined using PFGE. PFGE can be used to separate large DNA fragments efficiently and it has been used for the genomic investigations of different strains of bacteria and phage [73]. In order to prevent DNA shearing that might result from handling large DNA molecule, the phage particle was embedded in PFGE plugs prior to lysis. Genomic DNA was estimated at 68,854 bp in size which corresponds to the genomic sizes of the majority of the Podoviridae in the NCBI database. Contrary to the previous assumptions that the Podoviridae are the least common phage among the Caudovirales, all of the isolated phages belong to this genus.

Further genomic characterisation was done in order to assess the diversity among the phages based on restriction fragment length polymorphism (RFLP) by the use of restriction enzymes to digest the phage DNA in situ. This was done in order to avoid shearing problems associated with restriction digestion of large DNA molecules. RFLP analysis has been employed in the assessment of genetic diversity among bacteriophages [74, 75]. A previous study has reported the susceptibility of phage genome to the enzymes (NdeI and SspI) employed in this study [27]. Successful restriction enzyme digestion observed in this study confirmed that indeed phage genome was a double stranded DNA, a defining characteristic of the tailed phages (Caudovirales). Despite this, the restriction enzymes employed for this analysis could not differentiate between the phages as similar patterns were observed in them. Similarly, morphological identification by TEM also revealed the similarity among these phages. Interestingly, phages with similar digestion profiles and comparable appearances differed in their lytic ability against environmental E. coli O157:H7 strains. This could be as a result of the high degree of homology that is shared among phages with similar genome sizes 
[76]. Considering the similarities observed in these phages, it is suggested that they undergo genome sequencing and analysis so as to have an insight into the relatedness observed in this study.

\section{Conclusions}

In conclusion, three strong, stable and virulent lytic bacteriophages against E. coli O157:H7 were isolated and characterised in this study. The phages belonged to the family Podoviridae, with rapid growth rate and similar restriction enzyme patterns. They demonstrated thermal stabilities and were able to survive in a wide range of $\mathrm{pH}$ levels. They can be considered as promising candidates in the biocontrol of an emerging food-borne pathogen E. coli O157:H7 Although the phages showed reduced lytic spectrum against environmental E. coli O157:H7, they can be combined in phage cocktails to increase the area of application and control a wider range of E. coli O157:H7 strains especially the virulent strains. Future research should be directed to sequencing of the whole genomes so as to ascertain their safety in biocontrol and to the optimization of cocktails concentration that can be used to cause complete inhibition of E. coli O157:H7 in both artificial media and real food systems.

Author Contributions: Conceptualization, C.N.A and M.A.A; Performed the experiments, M.A.A; Data analysis, C.N.A and M.A.A; Writing-Review and Editing, C.N.A and M.A.A; Supervision, C.N.A.

Funding: This work was supported in part by National Research Foundation of South Africa [Grant UID Numbers 89228 and 98983].

Acknowledgments: This study was also supported by the North-West University, South Africa. The authors also acknowledge the support of Dr A. Jordan from the Laboratory for Electron Microscopy Chemical Resource Beneficiation at the North-West University, Potchefstroom campus in providing the transmission electron micrographs of the phages. We thank Dr L Ngoma and Mrs T Ateba for assistance with sample collection. Our gratitude also goes to Dr L. Chidamba at the University of Pretoria, South Africa for helping with genomic analysis of phage DNA.

Conflicts of Interest: The authors declare no conflict of interest.

\section{References}

1. Browning, N.; Botha, J.; Sacho, H.; Moore, P. Escherichia coli O157: H7 haemorrhagic colitis. Report of the first South African case. S. Afr. J. Surg. 1990, 28(1), 28-9. 
2. Effler, E.; Isaäcson, M.; Arntzen, L.; Heenan, R.; Canter, P.; Barrett, T.; Lee, L.; Mambo, C.; Levine, W.; Zaidi, A. Factors contributing to the emergence of Escherichia coli O157 in Africa. Emerg. Infect. Dis. 2001, 7(5), 812.

3. Reiss, G.; Kunz, P.; Koin, D.; Keeffe, E.B. Escherichia coli O157: H7 infection in nursing homes: review of literature and report of recent outbreak. J. Am. Geriatr. Soc. 2006, 54(4), 680-4.

4. Rangel, J.M.; Sparling, P.H.; Crowe, C.; Griffin, P.M.; Swerdlow, D.L. Epidemiology of Escherichia coli O157: $\mathrm{H7}$ outbreaks, United States, 1982-2002. Emerg. Infect. Dis. 2005, 11, 603-9.

5. Samadpour, M.; Ongerth, J.E.; Liston, J.; Tran, N.; Nguyen, D.; Whittam, T.S.; Wilson, R.A.; Tarr, P.I. Occurrence of Shiga-like toxin-producing Escherichia coli in retail fresh seafood, beef, lamb, pork, and poultry from grocery stores in Seattle, Washington. Appl. Environ. Microbiol. 1994, 60(3), 1038-40. 6. Ackers, M.-L.; Mahon, B.E.; Leahy, E.; Goode, B.; Damrow, T.; Hayes, P.S.; Bibb, W.F.; Rice, D.H.; Barrett, T.J.; Hutwagner, L. An outbreak of Escherichia coli O157: H7 infections associated with leaf lettuce consumption. J. Infect. Dis. 1998, 177(6), 1588-93.

7. Viazis, S.; Diez-Gonzalez, F. Enterohemorrhagic Escherichia coli: The Twentieth Century's Emerging Foodborne Pathogen: A Review. Adv. Agron 2011, 111, 1-50.

8. Cunin, P.; Tedjouka, E.; Germani, Y.; Ncharre, C.; Bercion, R.; Morvan, J.; Martin, P.M. An epidemic of bloody diarrhea: Escherichia coli O157 emerging in Cameroon? Emerg. Infect. Dis. 1999, 5(2), 285-90. PubMed PMID: PMC2640683.

9. Olorunshola, I.D.; Smith, S.I.; Coker, A.O. Prevalence of EHEC O157:H7 in patients with diarrhoea in Lagos, Nigeria. APMIS 2000, 108(11), 761-3.

10. Gwavava, C.; Chihota, V.N.; Gangaidzo, I.T.; Gumbo, T. Dysentery in patients infected with human immunodeficiency virus in Zimbabwe: an emerging role for Schistosoma mansoni and Escherichia coli O157? Ann. Trop. Med. Parasitol. 2001, 95(5), 509-13.

11. Mandomando, I.M.; Macete, E.V.; Ruiz, J.; Sanz, S.; Abacassamo, F.; Valles, X.; Sacarlal, J.; Navia, M.M.; Vila, J.; Alonso, P.L.; Gascon, J. Etiology of diarrhea in children younger than 5 years of age admitted in a rural hospital of southern Mozambique. Am. J. Trop. Med. Hyg. 2007, 76(3), 522-7. PubMed PMID: 17360878. Epub 2007/03/16. eng.

12. Ateba, C.N.; Mbewe, M.; Bezuidenhout, C.C. Prevalence of Escherichia coli O157 strains in cattle, pigs and humans in North West province, South Africa. S. Afr. J. Sci. 2008, 104(1-2), 7-8.

13. Chigor, V.N.; Umoh, V.J.; Smith, S.I.; Igbinosa, E.O.; Okoh, A.I. Multidrug Resistance and Plasmid Patterns of Escherichia coli O157 and Other E. coli Isolated from Diarrhoeal Stools and Surface Waters from Some Selected Sources in Zaria, Nigeria. Int. J. Environ. Res. Public Health 2010, 7(10), 3831-41. PubMed PMID: PMC2996195.

14. Lupindu, A.M. Epidemiology of Shiga toxin-producing Escherichia coli O157:H7 in Africa in review. South. Afr. J. Infect. Dis. 2018, 33(1), 24-30.

15. Sofos, J.N.; Belk, K.E.; Smith, G.C., editors. Processes to reduce contamination with pathogenic microorganisms in meat. 45 $5^{\text {th }}$ International Congress of Meat Science and Technology; 1999 August 1-6, 1999; Yokohama, Japan.

16. Hugas, M.; Tsigarida, E. Pros and cons of carcass decontamination: The role of the European Food Safety Authority. Meat Sci 2008, 78(1-2), 43-52. PubMed PMID: 22062094. Epub 2008/01/01. eng. 17. Newell, D.G.; Koopmans, M.; Verhoef, L.; Duizer, E.; Aidara-Kane, A.; Sprong, H.; Opsteegh, M.; Langelaar, M.; Threfall, J.; Scheutz, F. Food-borne diseases - the challenges of 20 years ago still persist while new ones continue to emerge. Int. J. Food Microbiol. 2010, 139, S3-S15. 
18. Loretz, M.; Stephan, R.; Zweifel, C. Antibacterial activity of decontamination treatments for cattle hides and beef carcasses. Food Control 2011, 22(3), 347-59.

19. Sofos, J.N.; Smith, G.C. Nonacid meat decontamination technologies: Model studies and commercial applications. Int. J. Food Microbiol. 1998, 44(3), 171-88.

20. Wheeler, T.L.; Kalchayanand, N.; Bosilevac, J.M. Pre- and post-harvest interventions to reduce pathogen contamination in the U.S. beef industry. Meat Sci. 2014, 98(3), 372-82.

21. Berry, E.D.; Cutter, C.N. Effects of acid adaptation of Escherichia coli O157: H7 on efficacy of acetic acid spray washes to decontaminate beef carcass tissue. Appl. Environ. Microbiol. 2000, 66(4), 1493-8.

22. Bueno, E.; García, P.; Martínez, B.; Rodríguez, A. Phage inactivation of Staphylococcus aureus in fresh and hard-type cheeses. Int. J. Food Microbiol. 2012, 158(1), 23-7.

23. Spricigo, D.A.; Bardina, C.; Cortés, P.; Llagostera, M. Use of a bacteriophage cocktail to control Salmonella in food and the food industry. Int. J. Food Microbiol. 2013, 165(2), 169-74.

24. Zinno, P.; Devirgiliis, C.; Ercolini, D.; Ongeng, D.; Mauriello, G. Bacteriophage P22 to challenge Salmonella in foods. Int. J. Food Microbiol. 2014, 191, 69-74.

25. Niu, Y.D.; McAllister, T.A.; Xu, Y.; Johnson, R.P.; Stephens, T.P.; Stanford, K. Prevalence and Impact of Bacteriophages on the Presence of Escherichia coli O157:H7 in Feedlot Cattle and Their Environment. Appl. Environ. Microbiol. 2009a, 75(5), 1271-8.

26. Kudva, I.T.; Jelacic, S.; Tarr, P.I.; Youderian, P.; Hovde, C.J. Biocontrol of Escherichia coli O157 with O157-Specific Bacteriophages. Appl. Environ. Microbiol. 1999, 65(9), 3767-73.

27. Raya, R.R.; Varey, P.; Oot, R.A.; Dyen, M.R.; Callaway, T.R.; Edrington, T.S.; Kutter, E.M.; Brabban, A.D. Isolation and Characterization of a New T-Even Bacteriophage, CEV1, and Determination of Its Potential To Reduce Escherichia coli O157:H7 Levels in Sheep. Appl. Environ. Microbiol. 2006, 72(9), 6405-10.

28. Viazis, S.; Akhtar, M.; Feirtag, J.; Brabban, A.D.; Diez-Gonzalez, F. Isolation and characterization of lytic bacteriophages against enterohaemorrhagic Escherichia coli. J. Appl. Microbiol. 2011, 110(5), 1323-31.

29. Hallewell, J.; Niu, Y.; Munns, K.; McAllister, T.; Johnson, R.; Ackermann, H.; Thomas, J.; Stanford, K. Populations of endemic bacteriophage differ between cattle shedding high and low numbers of Escherichia coli O157: H7 in feces. Appl. Environ. Microbiol. 2014, AEM. 00708-14.

30. Anany, H.; Brovko, L.Y.; El Arabi, T.; Griffiths, M.W. Bacteriophages as antimicrobials in food products: Applications against particular pathogens. In Handbook of Natural Antimicrobials for Food Safety and Quality, Taylor, T.M., Ed. Woodhead Publishing: Oxford,2015. pp. 89-116.

31. Koko, A.S.; Ackermann, H.W.; Taiwo, M.A.; Omilabu, S.A. Nigerian phages: the first bacteriophages from Tropical Africa. Afr. J. Microbiol. Res. 2011, 5(16), 2207-10.

32. Basdew, I.; Laing, M. Investigation of the lytic ability of South African bacteriophages specific for Staphylococcus aureus, associated with bovine mastitis. Biocontrol Sci. Techn. 2015, 25(4), 429-43.

33. Akindolire, M.A.; Ateba, C.N. Use of pulsed field gel electrophoresis genetic typing for tracing contamination with virulent Escherichia coli O157: H7 in beef-cattle producing farms. Gene Reports 2018, 13, 59-65.

34. Twest, R.V.; Kropinski, A.M. Bacteriophage Enrichment from Water and Soil. In Bacteriophages, Clokie, M.R.J., Kropinski, A.M., Eds.; Springer: NY, USA,2009, 1. pp. 15-21.

35. Sambrook, J.; Fritsch, E.F.; Maniatis, T. Molecular cloning: a laboratory manual. Cold spring harbor laboratory press: NY, USA, 1989; 0879693096. 
36. Carlson, K. Appendix: Working with Bacteriophages: Common Techniques and Methodological Approaches. In Bacteriophages: biology and applications, Kutter, E., Sulakvelide, A., Eds.; CRC Press: Boca Raton, USA,2005. pp. 428-85.

37. Yamamoto, K.R.; Alberts, B.M.; Benzinger, R.; Lawhorne, L.; Treiber, G. Rapid bacteriophage sedimentation in the presence of polyethylene glycol and its application to large-scale virus purification. Virology 1970, 40(3), 734-44.

38. Ackermann, H.W. Basic Phage Electron Microscopy. In Bacteriophages: Methods and Protocols, Clokie, M.R.J., Kropinski, A.M., Eds.; Springer: New York,2009, 1. pp. 113-26.

39. Harley, J.; Prescott, L. Laboratory Exercises in Microbiology, 2nd ed.; W.M.C. Brown Publishers: USA, 1993;

40. Ellis, E.L.; Delbrück, M. The growth of bacteriophage. J. Gen. Physiol. 1939, 22(3), 365-84.

41. Ackermann, H.-W. Bacteriophage observations and evolution. Res. Microbiol. 2003, 154(4), 24551.

42. O'Flynn, G.; Ross, R.P.; Fitzgerald, G.F.; Coffey, A. Evaluation of a Cocktail of Three Bacteriophages for Biocontrol of Escherichia coli O157:H7. Appl. Environ. Microbiol. 2004, 70(6), 341724.

43. Hagens, S.; Loessner, M.J. Bacteriophage for biocontrol of foodborne pathogens: calculations and considerations. Curr. Pharm. Biotechnol. 2010, 11(1), 58-68.

44. Mahony, J.; McAuliffe, O.; Ross, R.P.; van Sinderen, D. Bacteriophages as biocontrol agents of food pathogens. Curr. Opin. Biotechnol. 2011, 22(2), 157-63.

45. Clokie, M.R.J.; Millard, A.D.; Letarov, A.V.; Heaphy, S. Phages in nature. Bacteriophage 2011, 1(1), 31-45. PubMed PMID: PMC3109452.

46. Morita, M.; Tanji, Y.; Mizoguchi, K.; Akitsu, T.; Kijima, N.; Unno, H. Characterization of a virulent bacteriophage specific for Escherichia coli O157:H7 and analysis of its cellular receptor and two tail fiber genes. FEMS Microbiol. Lett. 2002, 211(1), 77-83.

47. Payne, R.J.; Jansen, V.A. Pharmacokinetic principles of bacteriophage therapy. Clin. Pharmacokinet. 2003, 42(4), 315-25.

48. Viazis, S.; Akhtar, M.; Feirtag, J.; Diez-Gonzalez, F. Reduction of Escherichia coli O157:H7 viability on leafy green vegetables by treatment with a bacteriophage mixture and transcinnamaldehyde. Food Microbiol. 2011, 28(1), 149-57.

49. Litt, P.K.; Jaroni, D. Isolation and Physiomorphological Characterization of Escherichia coli O157:H7-Infecting Bacteriophages Recovered from Beef Cattle Operations. Int. J. Microbiol. 2017, 2017, 7013236. PubMed PMID: PMC5662819.

50. Kutter, E. Phage host range and efficiency of plating. In Bacteriophages, Clokie, M.R.J., Kropinski, A.M., Eds.; Springer: NY, USA,2009. pp. 141-9.

51. Fortier, L.-C.; Sekulovic, O. Importance of prophages to evolution and virulence of bacterial pathogens. Virulence 2013, 4(5), 354-65.

52. Haaber, J.; Leisner, J.J.; Cohn, M.T.; Catalan-Moreno, A.; Nielsen, J.B.; Westh, H.; Penadés, J.R.; Ingmer, $\mathrm{H}$. Bacterial viruses enable their host to acquire antibiotic resistance genes from neighbouring cells. Nat. Commun. 2016, 7, 13333.

53. Kulikov, E.; Kropinski, A.M.; Golomidova, A.; Lingohr, E.; Govorun, V.; Serebryakova, M.; Prokhorov, N.; Letarova, M.; Manykin, A.; Strotskaya, A. Isolation and characterization of a novel indigenous intestinal N4-related coliphage vB_EcoP_G7C. Virology 2012, 426(2), 93-9. 
54. Ma, Y.; Li, E.; Qi, Z.; Li, H.; Wei, X.; Lin, W.; Zhao, R.; Jiang, A.; Yang, H.; Yin, Z.; Yuan, J.; Zhao, $X$. Isolation and molecular characterisation of Achromobacter phage phiAxp-3, an N4-like bacteriophage. Sci. Rep. 2016, 6, 24776. PubMed PMID: PMC4837373.

55. Bigwood, T.; Hudson, J.; Billington, C.; Carey-Smith, G.; Heinemann, J. Phage inactivation of foodborne pathogens on cooked and raw meat. Food Microbiol. 2008, 25(2), 400-6.

56. Carey-Smith, G.V.; Billington, C.; Cornelius, A.J.; Hudson, J.A.; Heinemann, J.A. Isolation and characterization of bacteriophages infecting Salmonella spp. FEMS Microbiol. Lett. 2006, 258(2), 182-6.

57. Ceyssens, P.-J.; Brabban, A.; Rogge, L.; Lewis, M.S.; Pickard, D.; Goulding, D.; Dougan, G.; Noben, J.-P.; Kropinski, A.; Kutter, E. Molecular and physiological analysis of three Pseudomonas aeruginosa phages belonging to the "N4-like viruses". Virology 2010, 405(1), 26-30.

58. Shin, H.; Lee, J.-H.; Kim, H.; Choi, Y.; Heu, S.; Ryu, S. Receptor diversity and host interaction of bacteriophages infecting Salmonella enterica serovar Typhimurium. PloS one 2012, 7(8), e43392.

59. Ackermann, H.W. Bacteriophage electron microscopy. Adv. Virus Res. 2012, 82, 1-32. PubMed PMID: 22420849. Epub 2012/03/17. eng.

60. Aprea, G.; D'Angelo, A.R.; Prencipe, V.A.; Migliorati, G. Bacteriophage Morphological Characterization by Using Transmission Electron Microscopy. J. Life Sci. 2015, 9, 214-20.

61. Ackermann, H.-W. Tailed bacteriophages: the order Caudovirales. In Adv. Virus Res., Elsevier: 1998, 51. pp. 135-201.

62. Ackermann, H.-W. Frequency of morphological phage descriptions in the year 2000. Arch. Virol. 2001, 146(5), 843-57.

63. Lu, Z.; Breidt, F. Escherichia coli O157:H7 bacteriophage $\Phi 241$ isolated from an industrial cucumber fermentation at high acidity and salinity. Front. Microbiol. 2015, 6, 67. PubMed PMID: PMC4330901.

64. Niu, Y.D.; Stanford, K.; Ackermann, H.-W.; McAllister, T.A. Characterization of 4 T1-like lytic bacteriophages that lyse Shiga-toxin Escherichia coli O157: H7. Can. J. Microbiol. 2012, 58(7), 923-7.

65. Lee, Y.-D.; Park, J.-H. Characterization and application of phages isolated from sewage for reduction of Escherichia coli O157: H7 in biofilm. LWT-Food Sci. Technol. 2015, 60(1), 571-7.

66. Guttman, B.; Raya, R.; Kutter, E. Basic phage biology. In Bacteriophages: Biology and applications, Kutter, E., Sulakvelide, A., Eds.; CRC Press: Boca Ration,2005, 4. pp. 28.

67. Ackermann, H.-W.; Tremblay, D.; Moineau, S. Long-term bacteriophage preservation. WFCC Newsletter 2004, 38, 35-40.

68. Hazem, A. Effects of temperatures, $\mathrm{pH}$-values, ultra-violet light, ethanol and chloroform on the growth of isolated thermophilic Bacillus phages. New Microbiol. 2002, 25(4), 469-76.

69. Fan, N.; Qi, R.; Yang, M. Isolation and characterization of a virulent bacteriophage infecting Acinetobacter johnsonii from activated sludge. Res. Microbiol. 2017, 168(5), 472-81.

70. Smolarska, A.; Rabalski, L.; Narajczyk, M.; Czajkowski, R. Isolation and phenotypic and morphological characterization of the first Podoviridae lytic bacteriophages $\phi A 38$ and $\phi A 41$ infecting Pectobacterium parmentieri (former Pectobacterium wasabiae). Eur. J. Plant Pathol. 2018, 150(2), 413-25.

71. Jończyk, E.; Kłak, M.; Międzybrodzki, R.; Górski, A. The influence of external factors on bacteriophages. Folia Microbiol. 2011, 56(3), 191-200.

72. Evilevitch, A.; Lavelle, L.; Knobler, C.M.; Raspaud, E.; Gelbart, W.M. Osmotic pressure inhibition of DNA ejection from phage. Proceedings of the National Academy of Sciences 2003, 100(16), 9292-5. 
73. Carrillo, C.M.L.; Connerton, P.L.; Pearson, T.; Connerton, I.F. Free-range layer chickens as a source of Campylobacter bacteriophage. Antonie Van Leeuwenhoek 2007, 92(3), 275.

74. Carlson, K. Working with bacteriophages: common techniques and methodological approaches. CRC Press Boca Raton, FL: 2005;

75. Akhtar, M.; Viazis, S.; Diez-Gonzalez, F. Isolation, identification and characterization of lytic, wide host range bacteriophages from waste effluents against Salmonella enterica serovars. Food Control 2014, 38(0), 67-74.

76. Chopin, A.; Bolotin, A.; Sorokin, A.; Ehrlich, S.D.; Chopin, M.-C. Analysis of six prophages in Lactococcus lactis IL1403: different genetic structure of temperate and virulent phage populations. Nucleic Acids Res. 2001, 29(3), 644-51. 